\title{
Five-minute test to prevent postcardiotomy reexploration
}

Shingo Kunioka, MD, ${ }^{\mathrm{a}}$ Tomonori Shirasaka, MD, PhD, ${ }^{\mathrm{a}}$ Masahiko Narita, MD, ${ }^{\mathrm{a}}$ Keisuke Shibagaki, MD, ${ }^{\mathrm{a}}$ Yuta Kikuchi, MD, ${ }^{\mathrm{a}}$ Yasuaki Saijo, MD, PhD, ${ }^{\mathrm{b}}$ and Hiroyuki Kamiya, MD, $\mathrm{PhD}^{\mathrm{a}}$

\section{ABSTRACT}

Objective: To evaluate the effectiveness of the 5-minute test (FMT), developed to record the amount of pericardial bleeding in patients undergoing general cardiac surgery, and determine the relationship between this test and postcardiotomy bleeding.

Methods: The medical records of 573 patients who underwent adult cardiac surgery between January 2016 and December 2019 were reviewed retrospectively. Patients were divided into 2 groups: the FMT group included patients who underwent general cardiac surgery between January 2018 and December $2019(n=278)$, and the control group included patients who underwent general cardiac surgery between January 2016 and December $2017(n=295)$. The postcardiotomy reexploration rate due to intrapericardial bleeding or cardiac tamponade within 1 week after surgery and the amount of bleeding until 2 days after surgery were compared. The FMT procedure involved counting the amount of bleeding by packing 4 to 6 surgical gauze sheets for 5 minutes. Sternal closure was performed when the amount of blood measured by the FMT was $<100 \mathrm{~g}$.

Results: Compared with the control group, the FMT group had a significantly lower incidence of postcardiotomy reexploration ( $1.5 \%$ vs $5.7 \% ; P=.007)$ and a reduced amount of bleeding after cardiac surgery (median, $1165 \mathrm{~mL}$ [interquartile range (IQR), 756.2-1743.8 $\mathrm{mL}$ ] versus $1440 \mathrm{~mL}[\mathrm{IQR}, 825.0-2130.0 \mathrm{~mL}] ; P=.005)$. There was a significant positive correlation between the FMT gauze sheet weight and postcardiotomy bleeding $(r=0.322 ; P<.001)$.

Conclusions: The FMT is an objective and effective tool for estimating postoperative bleeding during cardiac surgery that can prevent postcardiotomy reexploration and reduce the amount of postcardiotomy bleeding. (JTCVS Techniques 2022;12:121-9)

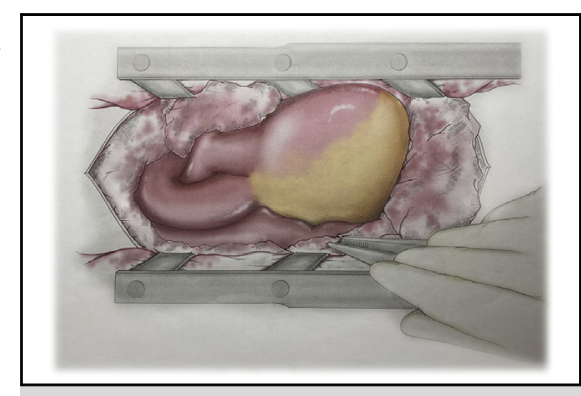

The 5-minute test reduces the need for postcardiotomy reexploration for bleeding.

CENTRAL MESSAGE

The 5-minute bleeding test is an effective criterion to prevent postcardiotomy reexploration before sternal closure and is significantly correlated with the amount of postcardiotomy bleeding.

\section{PERSPECTIVE}

Criteria for evaluating the amount of surgical bleeding are lacking. Traditionally, evaluation of surgical bleeding was based on the surgeon's experience, which might be subjective. The 5minute bleeding test is an objective method to evaluate the amount of bleeding, which can assist the surgeon's decision regarding when to perform sternal closure.

See Commentaries on pages 130 and 131.
To view the AATS Annual Meeting Webcast, see the URL next to the webcast thumbnail.

From the ${ }^{\mathrm{a} D e p a r t m e n t}$ of Cardiac Surgery and ${ }^{\mathrm{b}}$ Division of Public Health and Epidemiology, Department of Social Medicine, Asahikawa Medical University, Asahikawa, Japan.

Read at the 101st Annual Meeting of The American Association for Thoracic Surgery: A Virtual Learning Experience, April 30-May 2, 2021.

Received for publication March 27, 2021; accepted for publication Aug 16, 2021; available ahead of print Jan 19, 2022.

Address for reprints: Tomonori Shirasaka, MD, PhD, Department of Cardiac Surgery, Asahikawa Medical University, Midorigaoka Higashi 2-1-1-1, Asahikawa 0788510, Japan (E-mail: shira.skyrocket@gmail.com).

2666-2507

Copyright (c) 2022 The Author(s). Published by Elsevier Inc. on behalf of The American Association for Thoracic Surgery. This is an open access article under the CC BY-NC-ND license (http://creativecommons.org/licenses/by-nc-nd/4.0/).

https://doi.org/10.1016/j.xjtc.2021.08.049
Postcardiotomy tamponade is a life-threatening condition in perioperative care that requires emergency reexploration to stop the bleeding and provide hemodynamic stabilization. Cardiac surgeons have attempted to prevent this condition according to their own experience; however, there is no 


\section{Abbreviations and Acronyms \\ $\mathrm{CHF}=$ chronic heart failure \\ $\mathrm{CPB}=$ cardiopulmonary bypass \\ FMT $=5$-minute test \\ $\mathrm{ICU}=$ intensive care unit}

reliable standard for eliminating the excessive bleeding. The reported incidence of returning to the operating room due to postcardiotomy reexploration for bleeding is $2.0 \%$ to $4.2 \%$ in patients who have undergone cardiac surgery. ${ }^{1-4}$ Postcardiotomy reexploration is associated with adverse outcomes, prolonged intensive care unit (ICU) stay, the requirement for an intra-aortic balloon pump, ${ }^{3}$ arrhythmias, ${ }^{5}$ deep sternal wound infections, ${ }^{6,7}$ higher mortality rate, longer mechanical ventilation time, higher rate of blood transfusion, ${ }^{8}$ and higher costs. ${ }^{9}$ To reduce postcardiotomy bleeding complications, many previous studies have reported attempts to prevent the need for reexploration and to reduce the amount of bleeding and blood product consumption after cardiac surgery by adjusting medications ${ }^{10-13}$ or improving perioperative management ${ }^{14-18}$; however, to the best of our knowledge, there is no established methodology for estimating the amount of excessive postcardiotomy bleeding during cardiac surgery. We developed the 5-minute test (FMT), in which the amount of bleeding during cardiac operation is recorded before chest closure. In the present study, we aimed to estimate the effectiveness of the FMT to prevent postcardiotomy reexploration.

\section{METHODS}

\section{Ethical Approval}

This study was approved by the Ethics Committee of our hospital on November 30, 2020 (approval number: 20192), and was performed in accordance with the guidelines laid down by the 1964 Declaration of
Helsinki. Given the retrospective, observational nature of the study design, the Ethics Committee waived the requirement for informed consent.

\section{Study Design and Patient Selection}

This retrospective study reviewed the medical records of 750 patients who underwent adult cardiac surgery between January 2016 and December 2019 at Asahikawa Medical University Hospital. We excluded patients age $<18$ years, patients who had undergone minimally invasive cardiac surgery, and patients who had received an implanted left-ventricular assist device or extracorporeal membrane oxygenation support. Patients who had undergone reexploration for reasons other than bleeding (eg, additional coronary bypass grafting or adjustment of vessel graft position) were excluded as well.

After excluding 177 patients, the remaining patients were divided into 2 groups: the FMT group, comprising patients who underwent general cardiac surgery between January 2018 and December $2019(n=278)$, and the control group, comprising patients who underwent general cardiac surgery between January 2016 and December $2017(\mathrm{n}=295)$ (Figure 1). We began performing the FMT on January 1, 2018. This study was approved by the Ethics Committee of our hospital on November 30, 2020 (approval 20192).

We compared the rate of postcardiotomy reexploration due to intrapericardial bleeding or cardiac tamponade within 1 week after surgery and the amount of bleeding within 2 days after surgery between the FMT and control groups. We also identified which patients underwent postcardiotomy reexploration for bleeding and explored the causes of this bleeding.

\section{FMT Procedures and Decision Making for Chest Closure}

The FMT procedure is intended to assess the amount of bleeding in the pericardiac sac as an indication of surgical bleeding. The test is performed when surgeons are considering sternal closure. Because sternal closure can control bleeding from the bone marrow in the sternum, FMT focuses on assessing the amount of surgical and pericardial connective tissue bleeding during surgery. To minimize the amount of bleeding from the bone marrow in the sternum, 2 large towels are packed between the sternal retractor system and the sternotomy surfaces. Then 4 to 6 surgical dry gauze sheets are packed into the pericardial sac. As shown in the Central Picture, we usually pack the gauze sheets into both sides of the periaortic region and the right atrial and diaphragmatic sides of the pericardial sac. After 5 minutes, the gauze sheets are removed, and the number of sheets with blood are counted.

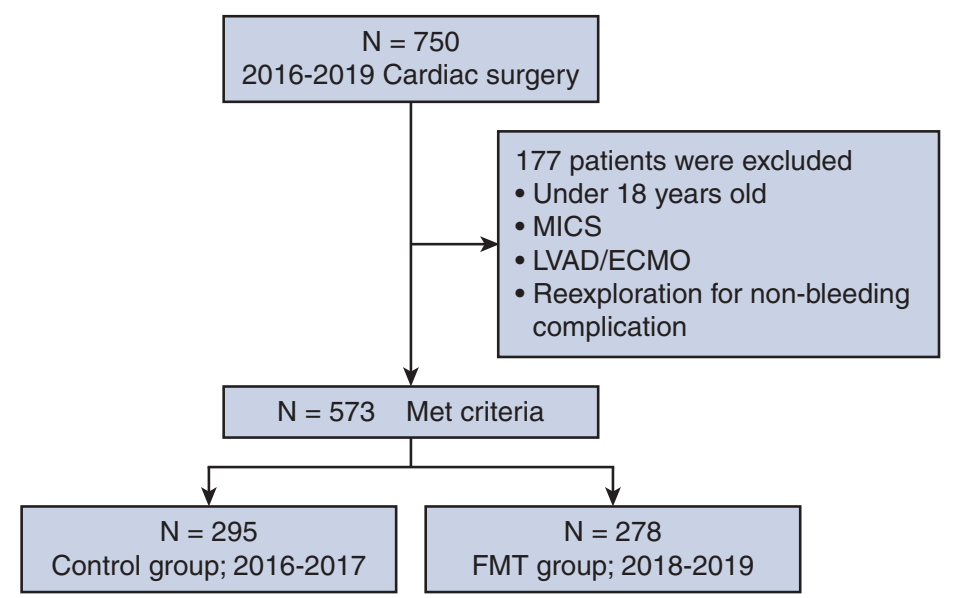

FIGURE 1. Patient selection and study flow. MICS, Minimally invasive cardiac surgery; $L V A D$, left ventricular assisting device; ECMO, extracorporeal membrane oxygenation; FMT, 5-minute test. 


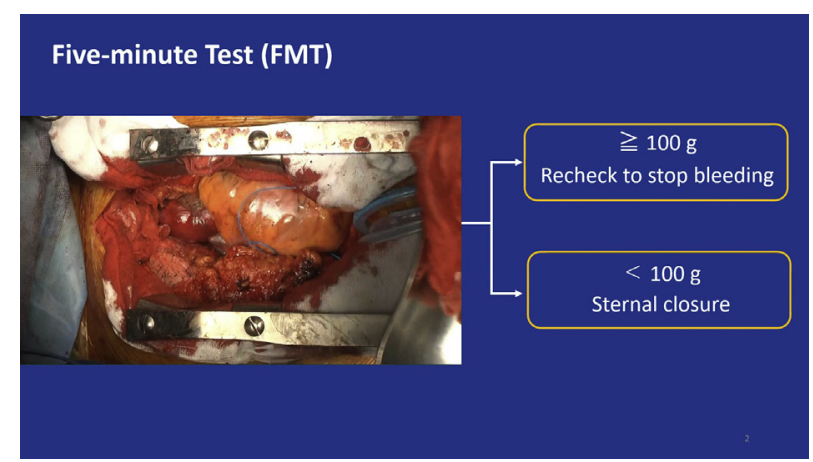

VIDEO 1. A brief video summary of the methodology, including how to apply the 5-minute test, and the main results of the study. Video available at: https://www.jtcvs.org/article/S2666-2507(22)00010-4/fulltext.

Each surgical gauze sheet weighs $3 \mathrm{~g}$; thus, we subtract the total weight of the gauze itself from the total weight of the gauze with blood. Sternal closure is performed when $<100 \mathrm{~g}$ of blood is collected during the FMT. If $>100 \mathrm{~g}$ is collected, the surgeon assesses the surgical field for bleeding and performs hemostasis as necessary. The FMT is repeated until the amount of blood collected during the FMT is controlled at $<100 \mathrm{~g}$. After the FMT procedure, the surgeon performs chest closure with approximately 6 sternal wires. Before completely closing the chest, the surgeon confirms the absence of bleeding from the sternum (Video 1).

\section{Postoperative Management and the Decision for Reexploration After Cardiac Surgery}

We usually administer $1000 \mathrm{mg}$ of tranexamic acid to all post-cardiac surgery patients when returning to the ICU. The decision to perform reexploration after cardiac surgery is made by the responsible surgeon according to the Kirklin and Barratt-Boyes criteria for reexploration ${ }^{19}$ : when the amount of bleeding is $>500 \mathrm{~mL}$ during the first hour, $>400 \mathrm{~mL}$ during each of the first 2 hours, $>300 \mathrm{~mL}$ during each of the first 3 hours; $>1000 \mathrm{~mL}$ during the first 4 hours, $>1200 \mathrm{~mL}$ during the first 5 hours, and on sudden massive bleeding or excessive bleeding. Hemodynamic collapse or persistent bleeding that does not improve is also considered. We investigated the amount of bleeding and blood transfusions provided after cardiac surgery. The amount of bleeding was recorded within 2 days postsurgery.

\section{Statistical Analyses}

Continuous variables are expressed as median and interquartile range (IQR) when non-normally distributed and as mean \pm standard deviation (SD) when normally distributed. The Mann-Whitney $U$ test was used for non-normally distributed variables, and the Student $t$ test was used for normally distributed variables. Categorical and sequential variables are expressed as percentage, and Fisher's exact test was used to compare the data between the 2 groups. Pearson's correlation analysis was performed

TABLE 1. Preoperative patient characteristics

\begin{tabular}{|c|c|c|c|}
\hline Characteristic & Control $(\mathbf{N}=\mathbf{2 9 5})$ & FMT $(\mathbf{N}=278)$ & $P$ value \\
\hline Age, $y$, mean \pm SD & $69.3 \pm 13.9$ & $68.1 \pm 14.2$ & .375 \\
\hline Male sex, $n(\%)$ & $160(53.9)$ & $161(57.9)$ & .448 \\
\hline Height, $\mathrm{cm}$, mean $\pm \mathrm{SD}$ & $156.7 \pm 15.7$ & $159.6 \pm 10.6$ & .014 \\
\hline Weight, $\mathrm{kg}$, mean $\pm \mathrm{SD}$ & $58.8 \pm 15.0$ & $61.9 \pm 14.5$ & .026 \\
\hline Body mass index, $\mathrm{kg} / \mathrm{m}^{2}$, mean $\pm \mathrm{SD}$ & $23.7 \pm 5.20$ & $24.1 \pm 4.73$ & .297 \\
\hline Hypertension, n (\%) & $199(67.0)$ & $203(73.6)$ & .110 \\
\hline Diabetes mellitus, n (\%) & $27(27.3)$ & $90(32.4)$ & .171 \\
\hline Insulin use, $\mathrm{n}(\%)$ & $27(9.1)$ & $29(10.4)$ & .672 \\
\hline Dyslipidemia, n (\%) & $147(49.5)$ & $139(50.0)$ & .931 \\
\hline Chronic lung disease, $\mathrm{n}(\%)$ & $23(7.7)$ & $22(7.9)$ & 1.00 \\
\hline Smoking habit, $\mathrm{n}(\%)$ & $79(26.6)$ & $93(33.5)$ & .079 \\
\hline $\mathrm{CKD}, \mathrm{n}(\%)$ & $66(22.2)$ & $72(25.9)$ & .327 \\
\hline Serum creatinine, $\mathrm{mg} / \mathrm{dL}$, mean $\pm \mathrm{SD}$ & $1.57 \pm 2.15$ & $1.69 \pm 2.13$ & .509 \\
\hline $\mathrm{eGFR}, \mathrm{mL} / \mathrm{min} / 1.73 \mathrm{~m}^{2}$, mean $\pm \mathrm{SD}$ & $57.9 \pm 28.8$ & $54.1 \pm 26.1$ & .111 \\
\hline Dialysis, n (\%) & $32(10.8)$ & $31(11.2)$ & .894 \\
\hline CHF, n $(\%)$ & $61(20.5)$ & $42(15.1)$ & .103 \\
\hline Recent myocardial infarction, $\mathrm{n}(\%)$ & $17(5.7)$ & $21(7.6)$ & .404 \\
\hline Unstable angina, $\mathrm{n}(\%)$ & $68(22.9)$ & $61(21.9)$ & .840 \\
\hline Extracardiac arteriopathy, n (\%) & $96(32.3)$ & $100(36.0)$ & .371 \\
\hline Preoperative stroke, n (\%) & $37(12.5)$ & $40(14.4)$ & .539 \\
\hline Active endocarditis, n (\%) & $13(4.4)$ & $10(3.6)$ & 675 \\
\hline Previous cardiac surgery, $\mathrm{n}(\%)$ & $44(14.8)$ & $23(8.3)$ & .584 \\
\hline Antiplatelet therapy, n (\%) & 85 (28.6) & $115(41.4)$ & .002 \\
\hline Anticoagulant therapy, $\mathrm{n}(\%)$ & $47(15.8)$ & $48(17.3)$ & .654 \\
\hline Euro score II, mean \pm SD & $6.16 \pm 7.41$ & $5.16 \pm 6.68$ & .108 \\
\hline
\end{tabular}

FMT, 5-minute test; $S D$, standard deviation; $C K D$, chronic kidney disease; $e G F R$, estimated glomerular filtration rate; $C H F$, chronic heart failure. 
to analyze the correlation between FMT results and postoperative bleeding. Multivariable logistic regression analysis of risk factors associated with reexploration for bleeding was used to examine the differences between the 2 groups. Missing data were handled by multiple imputation using the MICE package in the $\mathrm{R}$ version 4.0.4 (R Foundation for Statistical Computing, Vienna, Austria). A $P$ value $<.05$ was considered statistically significant. Statistical analyses were conducted using EZR software (Saitama Medical Center, Jichi Medical University, Saitama, Japan), a graphical user interface for R. ${ }^{20}$

\section{RESULTS}

The patients' preoperative characteristics are shown in Table 1. The FMT group were significantly taller (mean, $159.6 \pm 10.6 \mathrm{~cm}$ vs $156.7 \pm 15.7 \mathrm{~cm} ; P=.014)$ and heavier (mean, $61.9 \pm 14.5 \mathrm{~kg}$ vs $58.8 \pm 14.5 \mathrm{~kg} ; P=.026$ ) and had a significantly higher proportion of patients with a history of antiplatelet use $(41.4 \%$ vs $28.6 \% ; P=.002)$.

Intraoperative characteristics are summarized in Table 2. Regarding operative data, the FMT group had significantly lower rates of aortic surgery $(26.7 \%$ vs $44.1 \% ; P<.001)$ and valve surgery $(47.1 \%$ vs $64.1 \% ; P<.0001)$. Moreover, the operative time was significantly longer in the FMT group (median, 307 minutes [IQR, 257-390 minutes] vs 292 minutes [IQR, 233-381 minutes]; $P=.019$ ), whereas there was no significant difference in the time from off$\mathrm{CPB}$ to chest closure between the 2 groups. Intraoperative bleeding did not differ significantly between the 2 groups. Twenty-two patients underwent repeat FMT, with 16 patients undergoing the test twice and 6 doing so 3 times. A total of 36 patients underwent the operation without CPB; the proportion of patients without CPB was not significantly different between the 2 groups (control, 24\%; FMT, 12\%; $P=.084)$.

Postoperative patient characteristics are shown in Table 3. The FMT group had a significantly lower incidence of postcardiotomy reexploration $(1.5 \%$ vs $5.7 \% ; P=.007)$ (Figures 2, $A$ and 3 ) and a less bleeding after cardiac surgery (median, $1165 \mathrm{~mL}$ [IQR, 756.2-1743.8 mL] vs $1440 \mathrm{~mL}$ [IQR, 825.0$2130.0 \mathrm{~mL}$ ]; $P=.005$ ) (Figure $2, B$ ). There was a significant positive correlation between the weight of the FMT gauze sheets with blood and postcardiotomy bleeding $(r=.322$; $P<.001$ ) (Figure 2, C). There was no significant betweengroup difference in terms of blood transfusion.

The results of the multivariable logistic analysis are shown in Table 4. We assessed the factors associated with the rate of postcardiotomy reexploration for bleeding. FMT was independently associated with the rate of postcardiotomy reexploration for bleeding (odds ratio, $0.25 ; 95 \%$ confidence interval, $0.10-0.82 ; P=.020$ ). The other factors in the multivariable analysis were not statistically significant.

Causes of bleeding in the patients who underwent postcardiotomy reexploration are listed in Table 5. Twenty-one patients underwent postcardiotomy reexploration, including 17 from the control group and 4 from the FMT group. In the control group, $58.8 \%$ of the cases $(\mathrm{n}=10)$ involved cardiac and pericardial connective tissue, whereas in the FMT group, $25.0 \%(\mathrm{n}=1)$ involved the cardiac region. The amount of blood obtained in the FMT with postcardiotomy reexploration for bleeding ranged from $20 \mathrm{~g}$ to $92 \mathrm{~g}$. The cause of bleeding was of cardiac origin in 1 patient, of sternum origin in 1 patient, and unknown in the other 2 patients.

\section{DISCUSSION}

The key findings of the present study can be summarized as follows: 1) FMT can serve as a criterion for evaluating the amount of bleeding before sternal closure to prevent postcardiotomy reexploration, and 2) there was a significant positive correlation between the amount of blood according to the FMT and bleeding within 2 days post-cardiac surgery.

The present study found a significantly lower rate of reexploration after cardiac surgery in the FMT group compared with the control group. Postcardiotomy tamponade is a critical complication that necessitates a return to the operating room or immediate reexploration in the ICU to remove a blood clot removal and stop excessive bleeding. Because reexploration is a contributor to adverse outcomes, ${ }^{5-9}$ cardiac surgeons have continued to revise their surgical techniques, and numerous studies have addressed the optimal postoperative management to reduce postcardiotomy bleeding. ${ }^{10-18}$

TABLE 2. Perioperative variables

\begin{tabular}{|c|c|c|c|}
\hline Variable & Control $(\mathbf{N}=\mathbf{2 9 5})$ & FMT $(N=278)$ & $P$ value \\
\hline \multicolumn{4}{|l|}{ Operative procedures, $\mathrm{n}(\%)$} \\
\hline Coronary & $90(31.0)$ & $103(37.5)$ & .111 \\
\hline Valve & $186(64.1)$ & $129(47.1)$ & $<.001$ \\
\hline Aorta & $128(44.1)$ & $73(26.7)$ & $<.001$ \\
\hline Other & $44(15.2)$ & $41(15.0)$ & 1.00 \\
\hline Operative time, min, median (IQR) & $292(233-381)$ & $307(257-390)$ & .019 \\
\hline Aortic cross-clamp time, min, median (IQR) & $97(70.5-126)$ & $97.5(70.3-139.0)$ & .985 \\
\hline CPB time, min, median (IQR) & $147(114.5-182.5)$ & $145(112.5-184.6)$ & .867 \\
\hline Time from off-CPB to chest closure, min, median (IQR) & $97(71.0-127.0)$ & $94(74-122.5)$ & .676 \\
\hline Intraoperative bleeding, mL, median (IQR) & $1560(831.1-3293.0)$ & $1571(847.3-3147.8)$ & .894 \\
\hline
\end{tabular}

$F M T$, 5-minute test; $I Q R$, interquartile range; $C P B$, cardiopulmonary bypass. 
TABLE 3. Postoperative variables

\begin{tabular}{|c|c|c|c|}
\hline Variable & Control $(\mathbf{N}=295)$ & FMT $(\mathbf{N}=278)$ & $P$ value \\
\hline Reexploration due to bleeding complication, $\mathrm{n}(\%)$ & $17(5.7)$ & $4(1.5)$ & .007 \\
\hline Infection, n (\%) & $36(12.4)$ & $38(13.9)$ & .351 \\
\hline Prolonged ventilation $>21 \mathrm{~d}, \mathrm{n}(\%)$ & $24(8.2)$ & $23(8.4)$ & .518 \\
\hline Renal failure, $\mathrm{n}(\%)$ & $9(3.1)$ & $12(4.4)$ & .248 \\
\hline Stroke, n (\%) & $19(6.5)$ & $12(4.4)$ & .182 \\
\hline 30-d mortality, n (\%) & $12(4.1)$ & $13(4.7)$ & .416 \\
\hline Postoperative antiplatelet, n (\%) & $122(41.6)$ & $123(44.9)$ & .446 \\
\hline Postoperative anticoagulant, $\mathrm{n}(\%)$ & $223(76.1)$ & $205(74.8)$ & .770 \\
\hline \multicolumn{4}{|l|}{ Blood transfusion, mean $\pm \mathrm{SD}$} \\
\hline RBCs, units & $18.1 \pm 19.7$ & $17.7 \pm 14.4$ & 631 \\
\hline FFP, units & $20.3 \pm 25.4$ & $23.7 \pm 22.1$ & .053 \\
\hline PC, units & $31.0 \pm 51.3$ & $28.2 \pm 32.4$ & .860 \\
\hline Postoperative bleeding within $2 \mathrm{~d}$ postsurgery, $\mathrm{mL}$ & $1440(825.0-2130.0)$ & $1165(756.2-1743.8)$ & .005 \\
\hline
\end{tabular}

$F M T$, 5-minute test; $S D$, standard deviation; RBCs, red blood cells; FFP, fresh frozen plasma; $P C$, platelet concentrate.

However, estimating postcardiotomy bleeding is difficult, because it is generally evaluated subjectively by cardiac surgeons. Thus, we attempted to objectively estimate postcardiotomy bleeding during cardiac surgery. Additionally, many responsible surgeons do not consider necessary to close the sternum themselves, and occasionally a trainee or resident surgeon performs sternal closure on behalf of the responsible surgeon. In fact, less-experienced surgeons often perform sternal closure, which provides an educational opportunity for trainees and resident surgeons. Therefore, objective criteria for evaluating the amount of surgical bleeding before sternal closure are needed to maintain safe operative procedures.

The present study shows that the FMT can serve as an effective and objective criterion for evaluating the amount of intraoperative surgical bleeding, because it prevents postcardiotomy reexploration. The gauze also can provide information on the bleeding site location; for example, blood-soaked gauze near the right atrium suggests that the bleeding may be from the right atrial suture line of the right upper pulmonary vein venting suture.

Our present findings also suggest that FMT can reduce the amount of postcardiotomy bleeding. As shown in Figure 2, C, there is a significant positive correlation between the amount of bleeding during the FMT and postcardiotomy. This finding suggests that the amount of bleeding during the FMT and the amount of postcardiotomy bleeding are closely related; consequently, efforts to reduce the amount of bleeding in the FMT could contribute to reducing postcardiotomy bleeding. Although this result raises the possibility of reducing the amount of postcardiotomy transfusions, there was no difference in terms of blood transfusions between the 2 FMT and control groups. This might be because the volume of blood transfusions included all blood transfusions performed during the hospital stay. If patients were divided into those who required blood transfusion intraoperatively and those who required transfusion postoperatively, the findings might differ from our results. In our collected data, it was difficult to separate those who required blood transfusions intraoperatively from those who required them postoperatively. In many cases, blood transfusions are provided continuously from the operating room to the ICU, and thus it is not possible to separate intraoperative use from postoperative use. Therefore, transfusion volume might be greatly affected by the operative procedure.

Multivariable logistic analysis identified the FMT as an independent risk factor for reducing postcardiotomy reexploration for bleeding complications. In our analysis, these factors were selected with reference to previous reports suggesting that age, sex, preoperative renal insufficiency, procedures other than coronary surgery, prolonged CPB, emergency operation, prevalence of peripheral vascular disease, and preoperative exposure to aspirin could be associated with postoperative reexploration for bleeding. ${ }^{4,21,22}$

The FMT was suggested to more significantly reduce the rate of postcardiotomy reexploration compared with other confounding factors. Other factors, such as age, male sex, and prevalence of peripheral vascular disease, were not significantly different in the present study, in line with findings of the previous study. This might be related to our small sample size; originally, we did not aim to compare the results of postcardiotomy reexploration itself. In a study reported by Biancari and colleagues, ${ }^{22}$ surgical bleeding sites were identified in $65.7 \%$ of cases, and cardiac bleeding sites were identified in $40.9 \%$ of cases. Their meta-analysis concluded that meticulous surgical technique and systematic intraoperative checking of potential surgical bleeding sites at the time of the original cardiac surgery may reduce the risk of severe complications. The FMT can serve as a useful 


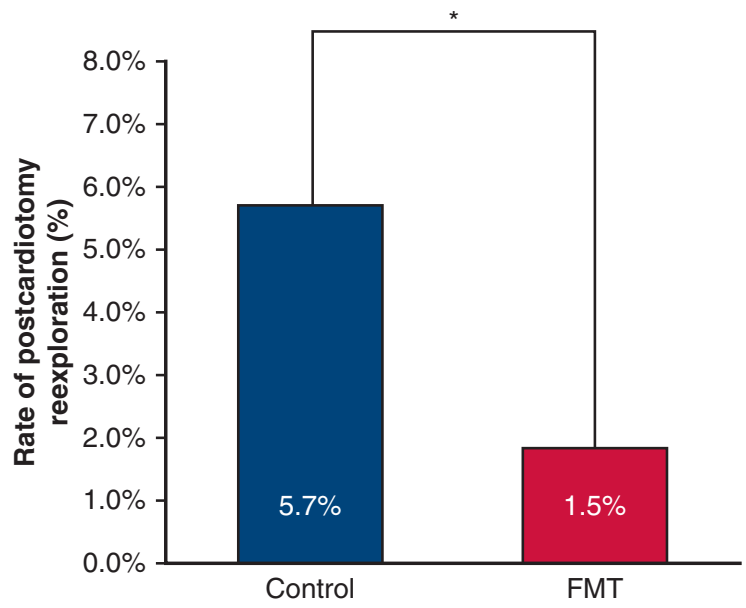

A

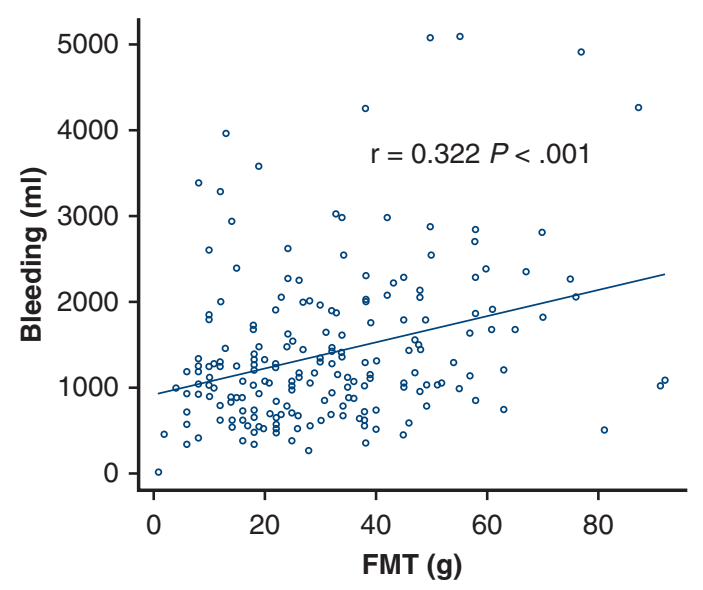

C

FIGURE 2. Postoperative findings. A, Postcardiotomy reexploration was significantly lower in the 5-minute test (FMT) group. B, The amount of bleeding after cardiac surgery was significantly lower in the FMT group. The upper and lower borders of the box represent the upper and lower quartiles, the middle horizontal line represents the median, the upper and lower whiskers represent the maximum and minimum values of nonoutliers. Extra dots represent outliers. C, Positive correlation between the weight of the FMT gauze sheets and postcardiotomy bleeding. D, The amount of FMT for each patient in FMT group; $85.6 \%$ of patients had a value $<50 \mathrm{~g}$.

final assessment tool for use after a systematic check of bleeding sites, because it can evaluate the amount of bleeding intraoperatively and provide a clear criterion in systematic bleeding assessment. It also can help surgeons be more aware of the presence of bleeding.

To ensure that bleeding has stopped, the FMT was repeated occasionally if $>100 \mathrm{~g}$ of bleeding was measured on the FMT. Use of the FMT might prolong the operative time. In the present study, the operative time was significantly longer in the FMT group compared with the control group; in contrast, there was no significant between-group difference in the time from off-CPB to chest closure. In 22 patients in this study, the FMT and hemostatic procedures were repeated during surgery; however, the times from off-CPB to chest closure were not prolonged. There

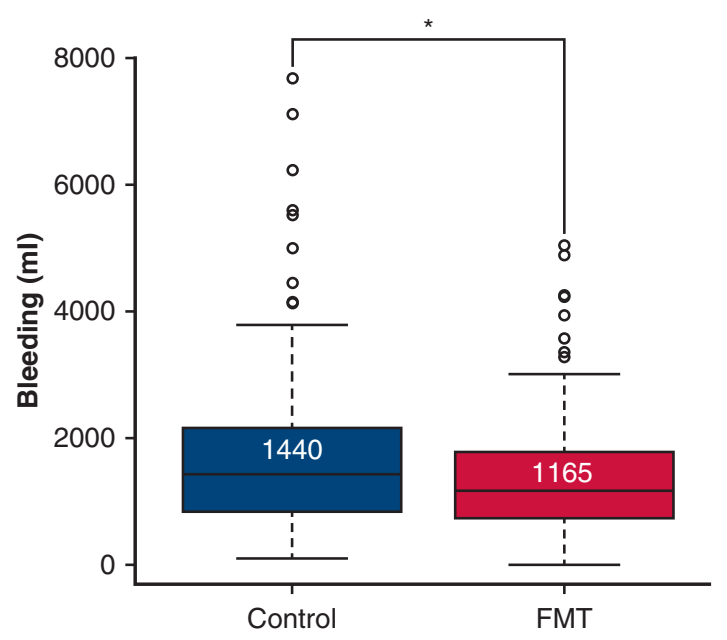

B

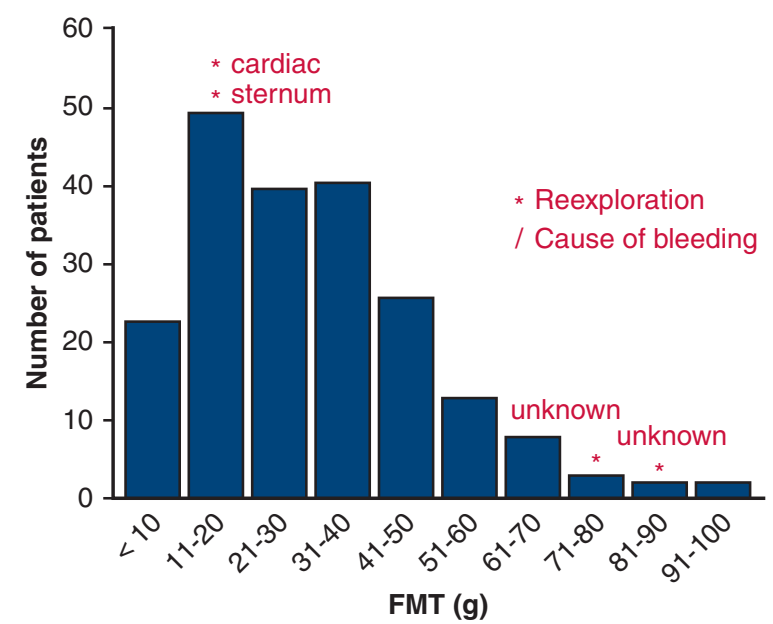

are 2 probable reasons this. First, the FMT took only $5 \mathrm{mi}-$ nutes to complete, and only 22 patients underwent repeat FMT; therefore, the extended time might not be reflected in the results of the present study. Second, we used the FMT as a criterion to decide when to perform chest closure; even if the FMT required only 5 minutes, surgeons did not waste their time worrying about whether they can close the sternum or if the amount of bleeding is acceptable. It is possible that the time from off-CPB to chest closure did not differ significantly because the surgeons in the control group had no decision criteria and were confused. The FMT offers a possibility for surgeons to be unconcerned about whether the amount of bleeding is acceptable before sternal closure if the cutoff is accurately defined. Regarding the time, 5 minutes is neither too long nor too short; rather, 
Five-minute Test (FMT)

Packing 4-6 surgical gauze sheets

Evaluate the amount of bleeding

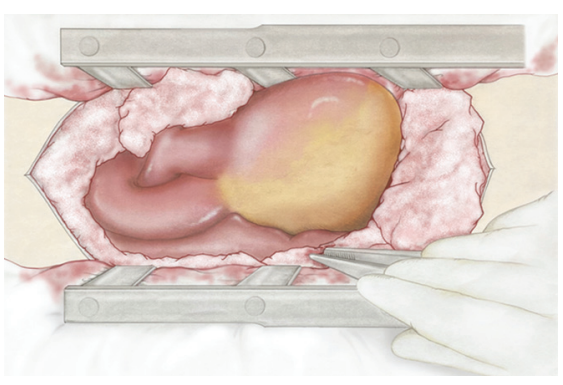

Postcardiotomy Reexploration

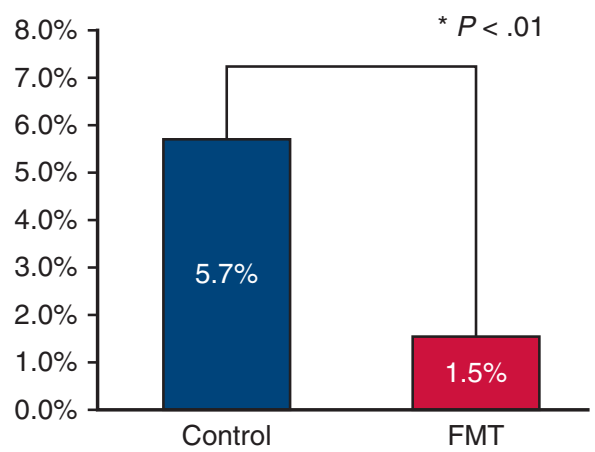

FIGURE 3. We retrospectively reviewed patients who underwent cardiac surgery between 2016 and 2019. We started the 5-minute test (FMT) in 2018. Therefore, the FMT group comprised patients operated in 2018 to 2019. The middle picture shows the procedure on how to apply the FMT (packing 4-6 surgical gauze sheets into the pericardial sac for 5 minutes). We evaluated the rate of postcardiotomy reexploration for bleeding within 1 week after cardiac surgery; the rate of reexploration for bleeding was significantly lower in the FMT group, decreasing from 5.7\% to $1.5 \%$. The FMT reduces the requirement for postcardiotomy reexploration for bleeding.

similar to the amount of bleeding, we consider it optimal to prevent prolonging the surgery. In this study, we defined a cutoff of $100 \mathrm{~g}$ for the amount of blood in the FMT based on previous reports. ${ }^{19,23}$ However, this criterion is related to postcardiotomy bleeding and is difficult to apply to bleeding during surgery. In fact, as shown in Figure 2, D, the amount of blood collected in the gauze tissue during the FMT was $<50 \mathrm{~g}$ in the majority of patients, suggesting that the cutoff value might have been set more strictly than that of the present study. Additional studies, including prospective studies, including larger sample sizes, are needed to investigate the optimal cutoff value and duration of the FMT.

The present study shows a significantly lower rate of reexploration after cardiac surgery in the FMT group compared with the control group; however, there were no significant differences between the 2 groups in terms of postoperative outcomes (ie, 30-day mortality and blood transfusion).

TABLE 4. Multivariable logistic regression analysis for risk factors associated with reexploration

\begin{tabular}{lcc}
\hline \multicolumn{1}{c}{ Risk factor } & OR $(\mathbf{9 5} \% \mathbf{C I})$ & $\boldsymbol{P}$ value \\
\hline Age $(\mathrm{y})$ & $0.99(0.96-1.02)$ & .404 \\
Male sex & $1.52(0.59-3.95)$ & .385 \\
Emergent surgery & $2.53(0.91-7.08)$ & .076 \\
History of cardiac surgery & $0.85(0.17-4.14)$ & .842 \\
\hline Chronic renal failure & $1.09(0.37-3.20)$ & .877 \\
Prevalence of peripheral vascular & $0.45(0.14-1.38)$ & .160 \\
\hline Antiplatelet therapy & $1.37(0.52-3.62)$ & .528 \\
Anticoagulant therapy & $1.66(0.56-4.86)$ & .359 \\
CPB time & $1.10(0.64-1.88)$ & .736 \\
FMT & $0.29(0.10-0.82)$ & .020 \\
\hline
\end{tabular}

$O R$, Odds ratio; $C I$, confidence interval, $C P B$, cardiopulmonary bypass, $F M T$, 5 -minute test.
Biancari and colleagues ${ }^{21}$ suggested that postcardiotomy reexploration is associated with a significantly increased risk of immediate postoperative mortality, stroke, need for an intraaortic balloon pump, acute renal failure, sternal wound infection, and prolonged mechanical ventilation. In the present study, the rate of reexploration was relatively higher than that of previous studies that reported decreases of $2.0 \%$ to $4.2 \% .{ }^{1-4}$ Our present findings are not significant in terms of postcardiotomy adverse events, except reexploration. In our institution, we do not hesitate to perform reexploration for cardiac tamponade before circulatory collapse with the support of the operating room staff, anesthesiologists, and perfusionists, which might increase the rate of postcardiotomy reexploration; however, use of the FMT improved the rate of reexploration for bleeding even with our positive attitude toward reexploration for cardiac tamponade. Originally, we did not aim to compare the results of postcardiotomy reexploration itself; thus, the FMT might not have contributed toward improving the 30day mortality and morbidity in this study.

Comparing the reasons for postcardiotomy reexploration for bleeding between the 2 groups shows that the rate of reexploration due to cardiac and pericardial connective tissue was lower in the FMT group compared with the control group;

TABLE 5. Causes of bleeding

\begin{tabular}{lcc}
\hline \multicolumn{1}{c}{ Cause of bleeding } & $\begin{array}{c}\text { Control } \\
(\mathbf{N}=\mathbf{1 7})\end{array}$ & $\begin{array}{c}\text { FMT } \\
(\mathbf{N}=\mathbf{4})\end{array}$ \\
\hline Cardiac/surgical, n (\%) & $6(35.3)$ & $1(25.0)$ \\
$\begin{array}{l}\text { Connective tissue, including } \\
\text { surrounding adipose tissue, } \mathrm{n}(\%)\end{array}$ & $4(23.5)$ & $0.0(0)$ \\
Sternum, n (\%) & $3(17.6)$ & $1(25.0)$ \\
Unknown, n (\%) & $4(23.5)$ & $2(50.0)$ \\
\hline
\end{tabular}

FMT, 5-minute test. 
however, the number of patients with postcardiotomy reexploration in the FMT group was too small $(n=4)$ for a statistical analysis of the difference. In our cohort, the causes of bleeding appeared to be less likely due to cardiac and pericardial connective tissue; therefore, performing the FMT could reduce the risk of postcardiotomy bleeding complications related to the pericardial region. Larger studies are needed to explore this possibility. The amount of blood collected during the FMT in the FMT group was also evaluated and the results varied among the patients. As mentioned above, the FMT might estimate postcardiotomy bleeding; however, the amount of bleeding could not be estimated because of the small number of patients who underwent postcardiotomy reexploration in the FMT group.

Limitations of this study include its retrospective nonrandomized design, single-center nature, and small sample size. Generally, even in a retrospective study, the sample size is calculated before starting; however, because this was a single-center study, the sample size was determined at the beginning of the study and was not calculated beforehand. Surgeon bias might have affected the outcome regarding the reexploration rate after cardiac surgery. However, surgeons are often cautious regarding performing reexploration for bleeding and often apply careful continuous hemostasis; thus, the impact of this bias would be expected to be small.

\section{CONCLUSIONS}

The FMT is an effective tool that is easy to perform in clinical practice to prevent postcardiotomy reexploration and reduce the amount of bleeding after cardiac surgery. FMT results are correlated with the amount of bleeding after cardiac surgery.

\section{Webcast}

You can watch a Webcast of this AATS meeting presentation by going to: https://aats.blob.core.windows.net/media/ Publications/AATS \%202021\%20Meeting \%20Kunioka\% 20and $\%$ 20Ferraris.mp4.

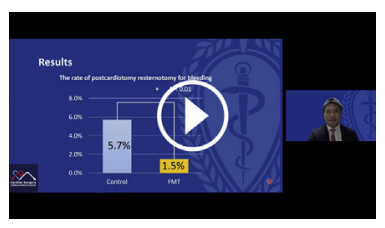

\section{Conflict of Interest Statement}

The authors reported no conflicts of interest.

The Journal policy requires editors and reviewers to disclose conflicts of interest and to decline handling or reviewing manuscripts for which they may have a conflict of interest. The editors and reviewers of this article have no conflicts of interest.

\section{References}

1. Russo AM, O'Connor WH, Waxman HL. Atypical presentations and echocardiographic findings in patients with cardiac tamponade occurring early and late after cardiac surgery. Chest. 1993;104:71-8.

2. Agarwal S, Choi SW, Fletcher SN, Klein AA, Gill R, Contributors. The incidence and effect of resternotomy following cardiac surgery on morbidity and mortality: a 1-year national audit on behalf of the Association of Cardiothoracic Anesthesia and Critical Care. Anesthesia. 2021;76:19-26.

3. Unsworth-White MJ, Herriot A, Valencia O, Poloniecki J, Smith EE, Murday AJ, et al. Resternotomy for bleeding after cardiac operation: a marker for increased morbidity and mortality. Ann Thorac Surg. 1995;59:664-7.

4. Moulton MJ, Creswell LL, Mackey ME, Cox JL, Rosenbloom M. Reexploration for bleeding is a risk factor for adverse outcomes after cardiac operations. $J$ Thorac Cardiovasc Surg. 1996;111:1037-46.

5. Creswell LL, Schuessler RB, Rosenbloom M, Cox JL. Hazards of postoperative atrial arrhythmias. Ann Thorac Surg. 1993;56:539-49.

6. Ottino G, De Paulis R, Pansini S, Rocca G, Tallone MV, Comoglio C, et al. Major sternal wound infection after open-heart surgery: a multivariate analysis of risk factors in 2,579 consecutive operative procedures. Ann Thorac Surg. 1987;44:173-9.

7. Kubota H, Miyata H, Motomura N, Ono M, Takamoto S, Hirai K, et al. Deep sternal wound infection after cardiac surgery. J Cardiothorac Surg. 2013; 8:132.

8. Ranucci M, Bozzetti G, Ditta A, Cotza M, Carboni G, Ballotta A. Surgical reexploration after cardiac operations: why a worse outcome? Ann Thorac Surg. 2008;86:1557-62.

9. Alström U, Levin LA, Ståhle E, Svedjeholm R, Friberg O. Cost analysis of reexploration for bleeding after coronary artery bypass graft surgery. Br J Anaesth. 2012;108:216-22.

10. Alaifan T, Alenazy A, Xiang Wang D, Fernando SM, Spence J, Belley-Cote E, et al. Tranexamic acid in cardiac surgery: a systematic review and metaanalysis (protocol). BMJ Open. 2019;9:e028585.

11. Filsoufi F, Castillo JG, Rahmanian PB, Scurlock C, Fischer G, Adams DH. Effec tive management of refractory postcardiotomy bleeding with the use of recombinant activated factor VII. Ann Thorac Surg. 2006;82:1779-83.

12. Stamou SC, Reames MK, Skipper E, Stiegel RM, Nussbaum M, Geller R, et al. Aprotinin in cardiac surgery patients: is the risk worth the benefit? Eur J Cardiothorac Surg. 2009;36:869-75.

13. Rousou J, Levitsky S, Gonzalez-Lavin L, Cosgrove D, Magilligan D, Weldon C et al. Randomized clinical trial of fibrin sealant in patients undergoing resternotomy or reoperation after cardiac operations. A multicenter study. J Thorac Cardiovasc Surg. 1989;97:194-203.

14. Hoffman WS, Tomasello DN, MacVaugh H. Control of postcardiotomy bleeding with PEEP. Ann Thorac Surg. 1982;34:71-3.

15. Grieshaber P, Heim N, Herzberg M, Niemann B, Roth P, Boening A. Active chest tube clearance after cardiac surgery is associated with reduced reexploration rates. Ann Thorac Surg. 2018;105:1771-7.

16. Ali JM, Gerrard C, Clayton J, Moorjani N. Hemostasis checklist reduces bleeding and blood product consumption after cardiac surgery. Ann Thorac Surg. 2021; 111:1570-7.

17. Lin C, Fu Y, Huang S, Zhou S, Shen C. Rapid thrombelastography predicts perioperative massive blood transfusion in patients undergoing coronary artery bypass grafting: a retrospective study. Medicine (Baltimore). 2020;99: e21833.

18. Meesters MI, Burtman D, van de Ven PM, Boer C. Prediction of postoperative blood loss using thromboelastometry in adult cardiac surgery: cohort study and systematic review. J Cardiothorac Vasc Anesth. 2018;32:141-50.

19. Kirklin JW, Barratt-Boyes BG, eds. Cardiac Surgery. New York: John Wiley and Sons; 1986:158-9.

20. Kanda Y. Investigation of the freely available easy-to-use software "EZR" for medical statistics. Bone Marrow Transplant. 2013:48:452-8.

21. Biancari F, Kinnunen EM, Kiviniemi T, Tauriainen T, Anttila V, Airaksinen JKE, et al. Meta-analysis of the sources of bleeding after adult cardiac surgery. J Cardiothorac Vasc Anesth. 2018;32:1618-24.

22. Biancari F, Mikkola R, Heikkinen J, Lahtinen J, Airaksinen KE, Juvonen T. Estimating the risk of complications related to reexploration for bleeding after adult cardiac surgery: a systematic review and meta-analysis. Eur J Cardiothorac Surg. 2012;41:50-5.

23. Dyke C, Aronson S, Dietrich W, Hofmann A, Karkouti K, Levi M, et al. Universal definition of perioperative bleeding in adult cardiac surgery. J Thorac Cardiovasc Surg. 2014;147:1458-63.e1. 
Key Words: postcardiotomy reexploration, cardiac tamponade, bleeding, complication, perioperative care

\section{Discussion}

\section{Presenter: Dr Shingo Kunioka.}

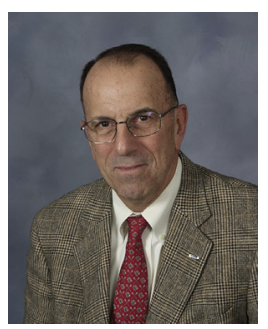

Dr Victor A. Ferraris (Lexington, Ky). The title of my commentary should be "patience is a virtue, but who said cardiothoracic surgeons are virtuous or patient." Please excuse the provocative rhetoric, but I suspect that the audience understands the need for action. A necessary prerequisite for the vast majority of cardiothoracic surgeons is an urgency to do good by doing something, usually this implies doing something active in the operating room or in the perioperative care.

We are not passive observers whose main job is to sit back and think about medical problems. We are trained to act since the very first time we appear in the operating room and the chief resident says "don't just stand there! Do something, get busy, prep the patient, then scrub your hands, and get your gown and gloves on." We have all been there.

The presentation by Kunioka and colleagues is hard to swallow. They suggest that we take some time at the end of a long and difficult operation to place packs around the heart and wait 5 minutes. Really, wait 5 minutes! Yes, and then continue to do that until the sponges are not bloodsoaked. Wow! I suspect that no one in this audience finds that 5-minute wait to be a simple chore. It comes at a time when the surgeon has spent several hours in the operating room performing a difficult, complex task.

I remember almost 50 years ago when the attending surgeon turned to me near the end of an operation and said "dry up and close the chest. I'll see you in the recovery room." Those days are gone forever, for at least 3 reasons:

- Operative complexity has changed.

- Care standards demand constant engagement by the responsible surgeon.

- Perhaps most importantly, no one is more knowledgeable about where the bleeding might be coming from and what can and needs to be done to control bleeding than the attending surgeon. The presentation by Professor Kunioka provides convincing evidence that a few minutes spent at the end of a difficult cardiac operation, employing a simple matter of placing packs around the heart and weighing sponges, can provide a meaningful improvement in bleeding complications.

I have 4 questions for the presenters:
1. First, have the authors considered any refinements or modifications of their techniques? Have they thought about adding some topical hemostatic agents to the pericardial surface? Topical hemostatic agents may speed up the process.

2. Are the authors' results impacted by the addition of intravenous agents that enhance hemostasis, such as Aprotinin or Amicar? How would they manage intravenous hemostatic agents?

3. Have the authors thought of other intraoperative techniques that may supplement this process? Are there refinements in the bypass circuit or the anesthetic management that can impact bleeding?

4. Are there certain operations that do not respond well to the authors' protocol. I'm thinking about operations for endocarditis or other complex procedures with increased bleeding risk from intrinsic patient coagulation or clotting defects. In other words, how would the authors modify their practice in patients with the highest bleeding risk? Is there a role for prophylactic clotting factors or other hemostatic agents?

Honestly, I'm surprised that a more rigorous, standardized assessment of bleeding before chest closure has not surfaced up until this presentation. Sometimes beneficial interventions are simple, and simple is better! Congratulations Dr Kunioka on a very provocative presentation.

Dr Percy Boateng (New York, NY). I'm sorry to interrupt you there, but we only have 1 minute for him to answer questions. Maybe we should jump to him to answer.

Dr Ferraris. Yes, of course.

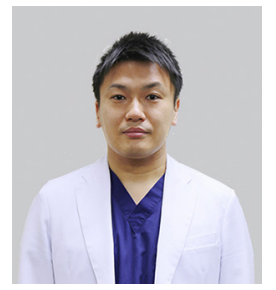

Dr Shingo Kunioka (Asahikawa, Japan). Thank you for your questions. For the first question, that's a great question, thank you for asking. We sometimes use topical hemostatic agents. The most common ones are fibrin sealant patch and fibrin glue. The present study did not examine that; howev-

er, those topical hemostatic agents may speed up the process.

As for your second question, we usually use drugs that enhance hemostasis, for example, fresh-frozen plasma, fibrinogen, recombinant factor VIIa in many cases. In many cases, anesthesiologist coordinates these use. We need to consider that impact of these factors.

For the next question, so far no interpretive techniques have been identified that would complement this process. But we always try to perform the surgery carefully to avoid bleeding in the first place.

For the final question, we recently had a case of resternotomy for bleeding caused by serious coagulopathy due to infectious endocarditis. In this case, 5 minutes was too short. However, postcardiotomy bleeding increased after return to the ICU. So I think the test cannot detect such cases.

Thank you very much. 